\title{
Results of Chordoma Patients Treated by Different Approaches in a Single Institution
}

\author{
Muge AKMANSU1 ${ }^{1}$, Gokhan KURT², Volkan DEMIRCAN ${ }^{1}$, Ertugrul SENTURK ${ }^{1}$ \\ ${ }^{1}$ Gazi University, School of Medicine, Department of Radiation Oncology, Ankara, Turkey \\ ${ }^{2}$ Gazi University, School of Medicine, Department of Neurosurgery, Ankara, Turkey \\ This study has been presented at the $11^{\text {th }}$ Multidisciplinary Neurooncology Symposium between 24 and 27 May 2018 at Mugla, Turkey.
}

Corresponding author: Volkan DEMIRCAN nvdemircan@hotmail.com

\section{ABSTRACT}

AIM: To discuss the optimal and recent treatment options based on clinical review of 16 chordoma patients.

MATERIAL and METHODS: Data of the patients diagnosed and treated between 1999 and 2017 in Gazi University School of Medicine has been collected through patients' files and the electronic database of hospital records. Statistical analysis was applied to evaluate the correlation between the progression free survival and treatment modalities.

RESULTS: Nine of the 16 patients were women (56.3\%). Half of the patients had intracranially located tumors, whereas the other $50 \%$ of the sample had spinal $(n=5)$ and sacral $(n=3)$ chordomas. The median follow-up time was 51.7 months. Recurrence was observed in $50 \%$ of patients, while the median recurrence time equaled to 27.6 months. Multivariate analysis results showed that age, gender tumor size, intra or extracranial location of tumor, treatment modalities, subtotal or grosstotal resection of tumor, radiotherapy dose, and techniques were not associated with recurrence. On the other hand, 2 patients are still under chemoterapy (imatinib, bevacizumab) without evident of recurrent disease.

CONCLUSION: Despite the fact that surgery remains to be the cornerstone of treatment, total resection is not reasonable for all patients with chordomas. For this reason, adjuvant treatment for ensuring local control is highly important. If the residual tumor is of a small volume, SBRT may provide more advantages. Targeted treatment or chemotheapeutic agents may also be benificial for maintanence therapy. As the clinical awareness about chordomas is based on our series, aggressive multi-modality treatment options should be applied in the adjuvant therapy.

KEYWORDS: Chordoma, Radiotherapy, Radiosurgery, Surgery, Imatinib, Bevacizumab

\section{INTRODUCTION}

$\longrightarrow$ hordomas are known as rare malign tumors typically present in the skull base, axial skeleton or sacrococcygeal region. They usually emerge from the remnants of embriyonic notochord (11). Chordoma is composed of $1-4 \%$ of all bone malignancies (18). It can be observed in the sacral region (50-60\%), followed by the skull base area (25-30\%) (7). It represents a tumor with lobules as well as vacuolated, moderately atypical, neoplastic cells across a myxoid stroma separated by fibrous bands. It mainly develops in the cranial and caudal ends of the axial skeleton, having quite a slow, aggressive and locally invasive character (10).

Despite the histologically low-grade nature of chordoma, this locally invasive characater of tumor causes malignant activity patterns and poses a high risk for recurrence of the disease. A wide surgical resection is still considered standard and primary treatment of chordomas, with application of postoperative radiotherapy for the residual macroscopic disease. En-bloc resection or any other resection of tumor cannot be operated because of the anatomical location of mass. In such cases,
Muge AKMANSU (D) : 0000-0002-5747-2522

Gokhan KURT : (1D):0000-0002-2773-056X
Volkan DEMIRCAN (10): 0000-0001-9632-180X

Ertugrul SENTURK (10): 0000-0002-7186-731X 
radiotherapy $(\mathrm{RT})$ becomes the principal treatment choice. On the other hand, published case series have revealed recurrence rates higher than $50 \%$ after gross total resection (GTR) of tumor with or without RT (23).

A slow-growing pattern of tumor requires the long-term follow-up for evaluation of recurrence free survival (RFS). The data on the long-term follow-up for chordomas is quite scarce in the medical literature. Moreover, designing prospective randomized studies for defining chordoma' optimal treatment is problematic due to rarity of the disease. Still, the literature provides quite a restricted data for long-term results. According to these sources, even after optimal treatment for local control of the disease, 5 and 10-year RFS for skull base chordomas are $47-76 \%$ and $42-71 \%$, respectively. In the meantime, 5 and $10-$ year estimated RFS for mobile spine chordomas are $58 \%$ and $32 \%$, respectively $(8,25,27)$. Similarly, 5,10 and 15 -year local relapse incidence for sacral chordomas is reported as $30 \%$, $46 \%$ and $57 \%$, respectively (19). It is obvious that chordomas are highly recurrent tumors in the long-term follow-up, while the medicine has not invented the gold standard therapy yet.

In this study, we intend to report results of 16 patients affected by chordoma in different areas who were treated by different approaches. The purpose is to compare outcomes with literature findings and thus select more optimal treatment option, possibly combined with newer approaches of chemotherapy.

\section{MATERIAL and METHODS}

The search over the electronic database in Gazi University School of Medicine and patients' files was operated to identify chordoma patients,. Data on 16 patients was completely accessible and fitted our criteria, covering the period between 1999 and 2017. SPSS (version 22.0) file was created with putting such information as age, gender, tumor size, intracranial or extracranial location of tumor, subtotal (STR) or total resection (TR) surgery type, RT dose, RT technique, chemotherapy, recurrence time and second line treatment modalities. Our patients' characteristics are shown in Table I.

All tumor-affected areas treated by surgery, radiosurgery, RT and chemotherapy were included in the study. The followup duration of each patient was determined according to the interval between the date of diagnosis and the date of last control examination by imaging modalities (MRI, CT). Recurrence of the disease was identified as relapse of the tumor at the same site after surgery or RT, or progression of the disease to adjacent structures from the primary site.

Statistical analysis was applied to identify the correlation between the factors in the SPSS file and progression free survival (PFS). Cox regression variables test was used for multivariate analysis.

\section{RESULTS}

The median age of patients was 51.6. Nine of patients (56.3\%) were women. Half of patients had intracranial chordoma. Most of tumors were bigger than $5 \mathrm{~cm}(62.5 \%) .15$ patients underwent surgery. Three of all patients had TR (18.75\%) and others have been irradiated postoperatively. Only 1 patient was treated with definitive RT. Some of patients were diagnosed with chordoma 20 years ago, approximately. Given the facts, our study included a heterogenous radiotherapy technique and doses related. Some of patients were treated with $2 \mathrm{D}$ conformal RT, whereas others were treated with 3Dconformal RT and IMRT, including RT doses of 50-54 Gy. In the meantime, the last two patients were irradiated by stereotactic radiotherapy (SBRT). Doses of these patients were $18 \mathrm{~Gy}$ in a fraction and 27 Gy in 3 fractions. We have observed recurrence of the disease in half of patients. The median recurrence time constituted 27.6 months (Figure 1).

Formally, 5-year PFS for our study has been $46.8 \%$ for 51.7 months of the median follow-up time. Tumor size, intracranial and extracranial location of tumor, TR or STR of the disease,

Table I: Demographic and Clinical Characteristics of Patients

\begin{tabular}{|c|c|}
\hline & Patient number $(n=16)$ \\
\hline Median age & $51.6(27-81)$ years \\
\hline \multicolumn{2}{|l|}{ Gender } \\
\hline Women & 9 \\
\hline Men & 7 \\
\hline \multicolumn{2}{|l|}{ Tumor site } \\
\hline Clivus & 6 \\
\hline Sacrum & 5 \\
\hline Spine & 3 \\
\hline Cranial & 2 \\
\hline \multicolumn{2}{|l|}{ Tumor size } \\
\hline$>5 \mathrm{~cm}$ & 10 \\
\hline$<5 \mathrm{~cm}$ & \\
\hline \multicolumn{2}{|l|}{ Surgery } \\
\hline Yes & 15 \\
\hline No & 1 \\
\hline \multicolumn{2}{|l|}{ Surgery type } \\
\hline GTR & 3 \\
\hline STR & 12 \\
\hline \multicolumn{2}{|l|}{ Radiotherapy } \\
\hline Yes & 12 \\
\hline No & 4 \\
\hline \multicolumn{2}{|l|}{ RT technique } \\
\hline $2 \mathrm{D}$ & 4 \\
\hline $3 \mathrm{D}$ & 4 \\
\hline IMRT & 2 \\
\hline SRS & 2 \\
\hline \multicolumn{2}{|l|}{ RT dose } \\
\hline 50 Gy & 6 \\
\hline 54 Gy & 2 \\
\hline \multicolumn{2}{|l|}{ Recurrence } \\
\hline Yes & 8 \\
\hline No & 8 \\
\hline
\end{tabular}




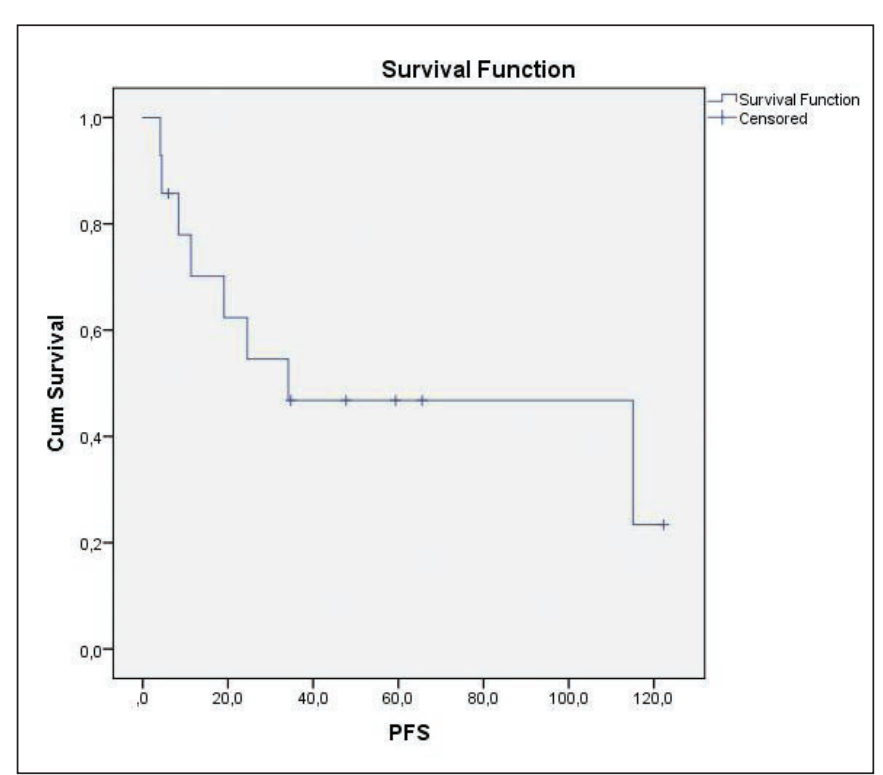

Figure 1: Survival function analysis of the 19 patients.

Table II: Factors That Affect Progression Free Survival (Cox Regression Analysis Results)

\begin{tabular}{ll}
\hline Parameters & p values \\
\hline Gender & 0.254 \\
\hline Age & 0.262 \\
\hline Tumor site & 0.319 \\
\hline Tumor size & 0.261 \\
\hline Surgery & 0.323 \\
\hline Surgery type & 0.342 \\
\hline Radiotherapy & 0.593 \\
\hline RT dose & $\mathrm{NS}$ \\
\hline RT technique & $\mathrm{NS}$ \\
\hline
\end{tabular}

age, gender, RT, RT doses, RT techniques were statistically analyzed with Cox regression variables test to identify the relationship between the risk factors and PFS. However, none of these risk factors were statistically associated with PFS (Table II). Nonetheless, the most important indicator is an ability to complete a surgical operation, specifically total resection.

\section{DISCUSSION}

Chordomas are malign embriyonic tumors that are disposed to local relaps, despite their histologically slow-growing pattern. Their locally invasive character may lead to a high recurrence risk, which makes a search of the optimal local treatment vital. Surgery with wide surgical margins and postoperative RT still remainsto be the first-choice treatment. Even though it is noted that en bloc resection of tumor with wide surgical margins improves local control of the disease, disease free survival (DFS) and disease related deaths with local recurrence (LR) rates for chordomas are ranging from $19 \%$ to $54 \%$ in the medical literature $(5,12,20,22)$. Considering the nature of tumor histology, it can be assumed that anatomical challenges that limit a wide excision of mass and put restrictions on RT doses to preserve the organ at risk might be a root cause of increased LR rates.

In concordance with that assumption, wide surgical margins for sacral chordoma can be ensured only for 35\%-75\% of patients. Moreover, this ratio reaches only $21 \%(3,4)$ for mobile spine. On the other hand, in the study titled "Chordoma Global Consessus", Stacchiotti et al. emphasized that 74 Gy RT dose is required to control the macroscopic disease in conventional fractionation due to the chordoma's radioresistant property (24). However, dose increase up to $74 \mathrm{~Gy}$ is not permissible at all periods of treatment. Such precautions are necessary to avoid complications in the adjacent critical structures. In fact, serious handicaps and limitations in selecting optimal treatment for local control persist. In our study, $75 \%$ of patients had STR and received postoperative RT in compliance with the literature. However, our study incorporates 16 different patients each having a different medical history. In this sense, it is not possible to make a proper comparison between the treatment approaches and descriptions of risk factors. On the other hands, we are able to provide certain interpretations and conclusions for the course of the disease, consequently defining the best approach for treatment with this retrospective case-control study.

Advancements in the technology of linear accelerators helped in ensuring higher doses of RT with almost $100 \%$ accurate target tracking, presenting a lesser amount of adverse effects. In addition, lack of the clear dose-response relationship has matched the side effects of RT in conventional fractionation occured for alternative treatments. Therefore, stereotactic radiotherapy (SBRT) and proton therapy make it possible to assign higher BED (biologically effective dose) with less toxicity. In this regard, several publications on this issue can be found useful. The first report of North American Gamma Knife Consortium has shown that $80 \%$ of patients survived for 5 years. This ratio would be $93 \%$ if no prior RT in treated people with single fraction was implemented (17). Fractionated SBRT may provoke reduced radiation toxicity to organs at risk and ensure safer treatment of mass with increased radiation dose. The 5-year local control rate for fractionated SRS with Cyber-knife is $60 \%$ and 5 -year OS rates are $53 \%-59 \%(13,16)$. Still, a recent study by Vasudevan et al. has reported that 3 -year LC and OS rates were $88 \%$ and $85 \%$ respectively with fractionated SBRT (26). Nevertheless, this study deals with serious limitations, such as the small sample size and short follow-up duration as compared to other studies focusing on chordoma. A new technology known as high dose proton therapy secures treatment with lower destruction of normal tissues. 5-year OS and LC rates for proton therapy are $72 \%-80 \%$ and $60 \%-81 \%$, respectively $(1,15)$. Despite its advantages in the radiobiology and a mild effect on normal tissues, proton therapy requires a lot of 
room and regular maintenance service to be fully operational. Evidently, it is a matter of high cost and expenditures, which can be a real obstacle for wide accessibility of this treatment option. Also, 5-year OS and LC rates (86\%-88\% and 65\%$88 \%$, respectively) are similar among patients treated with intensity modulated RT (21). We have 2 patients treated with SBRT in our study. One of these patients had the recurrent disease and received 18 Gy dose in a single fraction; the other one had inoperable chordoma and definitively treated with 27 Gy radiation dose in three fractions. Although there were no signs of the disease after SBRT for both patients, we failed to identify any significant statistical correlations because of the small sample size. In conclusion, when we referred to the literature for OS and LC rates for all kinds of radiation techniques, results have been found similar to each other. However, SBRT, fractionated or a single dose, as well as proton therapy may have some advantages for improving the theoritical background of radiobiology, such as treatment time effect on vascular tissues and preservation of normal tissues.

Originally, no chemotherapeutic agent effective for treating chordoma was actually identified for a long time. However, recent studies on imatinib mesylate, which is a tyrosine kinase inhibitor targeting platelet derived from growth factor receptorbeta (PDGFRB), BCL-ABL and KIT, have revealed noticeable benefits for the clinical course of the disease (6). Another study for advanced chordoma cases with using imatinib mesylate showed that imatinib provides $>70 \%$ tumor growth and arrest for progressive disease, ensuring progression free survival above 18 months in $>20 \%$ of patients (14). Some publications on bevacizumab, which is a vascular endothelial growth factor (VEGF) inhibitor, have also been available in treating chordoma patients. It has been reported that bevacizumab can be practically efficient in stabilizing the disease in a limited number of chordoma cases $(2,9)$. Relying on the data above, we used it in 2 patients who were under chemotherapeutic agents (1 patient with imatinib and 1 patient with bevacizumab) without any progression of the disease. One of them was assigned to external irradiation in addition to imatinib; the other one had to take 27Gy/3fr SBRT and adjuvant bevacizumab. Both patients have been monitored for 9 months and no recurrence has been identified by this moment.

\section{CONCLUSION}

Chordomas are found as rare, slow-growing, locally agressive, malignant embriyonic tumors present in skull base and axial skeleton. Despite the fact that surgery remains to be the primary treatment, total resection is the most typical factor of recurrence. Due to anatomical difficulties, a wide surgical excision is not allowed to all patients. For this reason, adjuvant treatment for securing local control is highly important. If the residual tumor is small, SBRT may be an advantageous choice. The use of newer targeted or chemotheapeutic agents may become helpful for maintanence therapy in the future. However, as the disease is rare in prevalence, randomized controlled phase 3 studies for optimal adjuvant approaches are not available to date. Still, our knowledge and awareness on chordomas is based on our series. Therefore, aggressive multi-modality treatment options can be applied in the adjuvant therapy.

\section{- REFERENCES}

1. Ares C, Hug EB, Lomax AJ, Bolsi A, Timmermann B, Rutz HP, Schuller JC, Pedroni E, Goitein G: Effectiveness and safety of spot scanning proton radiation therapy for chordomas and chondrosarcomas of the skull base: First long-term report. Int J Radiat Oncol Biol Phys 75:1111-1118, 2009

2. Asklund T, Sandström M, Shahidi S, Riklund K, Henriksson R: Durable stabilization of three chordoma cases by bevacizumab and erlotinib. Acta Oncol 53(7):980-984, 2014

3. Bergh P, Gunterberg B, Meis-Kindblom JM, Kindblom LG: Prognostic factors and outcome of pelvic, sacral, and spinal chondrosarcomas: A center-based study of 69 cases. Cancer 91:1201-1212, 2001

4. Boriani S, Bandiera S, Biagini R, Bacchini P, Boriani L, Cappuccio M, Chevalley F, Gasbarrini A, Picci P, Weinstein $\mathrm{JN}$ : Chordoma of the mobile spine: Fifty years of experience. Spine 31:493-503, 2006

5. Boriani S, Saravanja D, Yamada Y, Varga PP, Biagini R, Fisher CG: Challenges of local recurrence and cure in low grade malignant tumors of the spine. Spine 34:S48-57, 2009

6. Casali PG, Messina A, Stacchiotti S, Tamborini E, Crippa F, Gronchi A, Orlandi R, Ripamonti C, Spreafico C, Bertieri R, Bertulli R, Colecchia M, Fumagalli E, Greco A, Grosso F, Olmi P, Pierotti MA, Pilotti S: Imatinib mesylate in chordoma. Cancer 101(9):2086-2097, 2004

7. Chugh R, Tawbi H, Lucas DR, Biermann JS, Schuetze SM, Baker LH: Chordoma: The nonsarcoma primary bone tumor. Oncologist 12(11):1344-1350, 2007

8. Cloyd JM, Acosta FL Jr, Polley MY, Ames CP: En bloc resection for primary and metastatic tumors of the spine: $A$ systematic review of the literature. Neurosurgery 67:435-444, 2010

9. Di Maio S, Yip S, Al Zhrani GA, Alotaibi FE, Al Turki A, Kong E, Rostomily RC: Novel targeted therapies in chordoma: An update. Ther Clin Risk Manag 11:873-883, 2015

10. Ferraresi V, Nuzzo C, Zoccali C, Marandino F, Vidiri A, Salducca N, Zeuli M, Giannarelli D, Cognetti F, Biagini R: Chordoma: Clinical characteristics, management and prognosis of a case series of 25 patients. BMC Cancer 10:22, 2010

11. Flanagan AM, Yamaguchi T: Chordoma. In Fletcher CDM, Bridge JA, Pancras CW, Mertens F (eds), World Health Organization (WHO) Classification of Tumours of Soft Tissue and Bone. Pathology and Genetics. Lyon: IARC Press, 2013: 328-329

12. Gokaslan ZL, Zadnik PL, Sciubba DM, Germscheid N, Goodwin CR, Wolinsky JP, Bettegowda C, Groves ML, Luzzati A, Rhines LD, Fisher CG, Varga PP, Dekutoski MB, Clarke MJ, Fehlings MG, Quraishi NA, Chou D, Reynolds JJ, Williams RP, Kawahara N, Boriani S15: Mobile spine chordoma: Results of 166 patients from the AOSpine Knowledge Forum Tumor database. J Neurosurg Spine 24:644-651, 2016

13. Henderson FC, McCool K, Seigle J, Jean W, Harter W, Gagnon GJ: Treatment of chordomas with CyberKnife: Georgetown University experience and treatment recommendations. Neurosurgery 64:A44-53, 2009 
14. Hindi N, Casali PG, Morosi C, Messina A, Palassini E, Pilotti S, Tamborini E, Radaelli S, Gronchi A, Stacchiotti S: Imatinib in advanced chordoma: A retrospective case series analysis. Eur J Cancer 51(17): 2609-2614, 2015

15. Indelicato DJ, Rotondo RL, Begosh-Mayne D, Scarborough MT, Gibbs CP, Morris CG, Mendenhall WM: A prospective outcomes study of proton therapy for chordomas and chondrosarcomas of the spine. Int J Radiat Oncol Biol Phys 95:297-303, 2016

16. Jiang $B$, Veeravagu A, Lee M, Harsh GR, Lieberson RE, Bhatti I, Soltys SG, Gibbs IC, Adler JR, Chang SD: Management of intracranial and extracranial chordomas with CyberKnife stereotactic radiosurgery. J Clin Neurosci 19:1101-1106, 2012

17. Kano H, Igbal F, Sheehan J, Mathieu D, Seymour ZA, Niranjan A, Flickinger JC, Kondziolka D, Pollock BE, Rosseau G, Sneed PK, McDermott MW, Lunsford LD: Stereotactic radiosurgery for chordoma: A report from the North American Gamma Knife Consortium. Neurosurgery 68:379-388, 2011

18. McMaster ML, Goldstein AM, Bromley CM, Ishibe N, Parry DM: Chordoma: Incidence and survival patterns in the United States, 1973-1995. Cancer Causes Control 12(1):1-11, 2001

19. Radaelli S, Stacchiotti S, Ruggieri P, Donati D, Casali PG, Palmerini E, Collini P, Gambarotti M, Porcu L, Boriani S, Gronchi A, Picci P: Sacral chordoma: Long-term outcome of a large series of patient surgically treated at two reference centers. Spine 41:1049-1057, 2016

20. Ruggieri P, Angelini A, Ussia G, Montalti M, Mercuri M: Surgical margins and local control in resection of sacral chordomas. Clin Orthop Rel Res 468:2939-2947, 2010

21. Sahgal A, Chan MW, Atenafu EG, Masson-Cote L, Bahl G, Yu E, Millar BA, Chung C, Catton C, O'Sullivan B, Irish JC, Gilbert R, Zadeh G, Cusimano M, Gentili F, Laperriere NJ: Imageguided, intensity-modulated radiation therapy (IG-IMRT) for skull base chordoma and chondrosarcoma: preliminary outcomes. Neuro Oncol 17:889-894, 2015
22. Stacchiotti S, Casali PG, Lo Vullo S, Mariani L, Palassini E, Mercuri M, Alberghini M, Pilotti S, Zanella L, Gronchi A, Picci $P$ : Chordoma of the mobile spine and sacrum: A retrospective analysis of a series of patients surgically treated at two referral centers. Ann Surg Oncol 17:211-219, 2009

23. Stacchiotti S, Gronchi A, Fossati P, Akiyama T, Alapetite C, Baumann M, Blay JY, Bolle S, Boriani S, Bruzzi P, Capanna R, Caraceni A, Casadei R, Colia V, Debus J, Delaney T, Desai A, Dileo P, Dijkstra S, Doglietto F, Flanagan A, Froelich S, Gardner PA, Gelderblom H, Gokaslan ZL, Haas R, Heery C, Hindi N, Hohenberger P, Hornicek F, Imai R, Jeys L, Jones RL, Kasper B, Kawai A, Krengli M, Leithner A, Logowska I, Martin Broto J, Mazzatenta D, Morosi C, Nicolai P, Norum OJ, Patel S, Penel N, Picci P, Pilotti S, Radaelli S, Ricchini F, Rutkowski P, Scheipl S, Sen C, Tamborini E, Thornton KA, Timmermann B, Torri V, Tunn PU, Uhl M, Yamada Y, Weber DC, Vanel D, Varga PP, Vleggeert-Lankamp CLA, Casali PG, Sommer J: Best practices for the management of local-regional recurrent chordoma: A position paper by the Chordoma Global Consensus Group. Ann Oncol 28(6):1230-1242, 2017

24. Stacchiotti S, Sommer J: Chordoma global consensus G. Building a global consensus approach to chordoma: A position paper from the medical and patient community. Lancet Oncol 16:e71-83, 2015

25. Tzortzidis F, Elahi F, Wright D, Natarajan SK, Sekhar LN: Patient outcome at long-term follow-up after aggressive microsurgical resection of cranial base chordomas. Neurosurgery 59:230 237, 2006

26. Vasudevan HN, Raleigh DR, Johnson J, Garsa AA, Theodosopoulos PV: Management of chordoma and chondrosarcoma with fractionated stereotactic radiotherapy. Front Surg 4:35, 2017

27. Weber DC, Malyapa R, Albertini F, Bolsi A, Kliebsch U, Walser M, Pica A, Combescure C, Lomax AJ, Schneider R: Long term outcomes of patients with skull-base low-grade chondrosarcoma and chordoma patients treated with pencil beam scanning proton therapy. Radiother Oncol 120:169-174, 2016 